\title{
WAVE-CURRENT INTERACTION, SEDIMENT TRANSPORT AND SEABED EVOLUTION IN THE PIRAQUÊ-AÇU/PIRAQUÊ MIRIM ESTUARY (BRAZIL)
}

\author{
Thaís Nunes Coutinho ${ }^{1}$ Leonardo Carvalho de Jesus² and Julio Tomás Aquije Chacaltana ${ }^{3}$
}

\begin{abstract}
The medium-term seabed evolution of Piraquê-Açú/Piraquê-Mirim estuary (ES/Brazil) is studied numerically in this work. The hydrodynamics is induced by the tide, the river discharges, and the incident water wave. The wave-tidecurrent interactions are obtained by coupling the shallow water equations with the radiation stress tensor introduced by Longuet-Higgins \& Stewart (1960). In this way, the influence of both the tidal current and the current induced by gravity waves on the sediment transport are taken into account. We utilized the Exner (1925) equation, based on the conservation of seabed sediment mass, to calculate the morphological evolution. Seabed morphological changes are accelerated by introducing a time scale factor. Four bedload sediment transport formulations were tested and compared. We found an excellent agreement when numerical results are compared with currents measured in the upper estuary and with sediment transport rates measured at the river's mouth when using the Engelund and Hansen (1967) sediment transport formulation. We also found that the main morphological changes occurring at the estuary mouth are due to the action of gravity waves. Between the head and mouth of the estuary, the sediment transport rate and morphological seabed changes are controlled exclusively by the tidal currents and the river discharge. In this latter case, we found that the large sandbank located at the estuary mouth is responsible for the absence of wave.
\end{abstract}

Keywords: wave-current interaction; sediment transport, seabed evolution;

\section{INTRODUCTION}

Worldwide estuaries have a great importance for many human activities, e.g., harbor and navigation, fishing and aquaculture, tourism, and provide many other ecological services such as coastline protection, flood defense, and biodiversity conservation. Understanding the estuarine morphodynamics is crucial for the protection of coastal structures, logistic and management of water, living resources, and require a vast knowledge of various hydrodynamics processes acting in the estuary, like tidal induced currents, wave-current interactions, river discharges and sediment transport.

Several studies of the hydrodynamics and morphological changes in estuaries have focused on the effect of river discharge and tidal flow (van der Vegt et al., 2006, Bertin et al., 2009; Dissanayake et. al., 2009; Dissanayake et. al., 2012) in the absence of waves. In a wave-dominated environment process such as wave-breaking, wave induced currents, wave-current interaction, may play a significant role in the hydrodynamics and hence in the sediment transport and seabed evolution, especially in micro-tidal systems with low river discharge (Wang et. al., 1995; Cayocca, 2001; Dissanayake et. al., 2012; Kuang et al., 2013; Fortunato et al., 2014).

In recent years, considerable advances have been made in the simulation of the sediment transport and the seabed evolution. The models use dynamical equations of physical processes (hydrodynamics, waves and sediment transport) in separate modules for flow field and sediment transport (for example, Wang et al., 1995, Lesser et al., 2004; Ding et. al., 2006, Olabarrieta et al., 2014). Numerical models have the advantage of describing sediment transport in both time and space so that sediment dynamics can be evaluated over vast areas with a high temporal resolution. However, the development of sediment and morphodynamic models in the Brazilian coast is still at an initial stage.

The Piraquê-açu/Piraquê-mirim estuary is an incised-valley Y-shaped inlet in the Espírito Santo State located at the southeast Brazilian coast. It is an interesting and complex estuary, with a large ebbtidal delta sandbank on its mouth and low land sediment input. The micro-tidal regime of the estuary has a spring tide amplitude of approximately $1.2 \mathrm{~m}$ (Silva et al., 2013). Another characteristic is the multiple uses of the estuary including artisanal fishing, tourism, navigation and environmental protected areas.

In this work, we investigate the effect of the wave on coastal currents and sediment transport and the medium-term morphological evolution of the Piraquê-Açú/Piraquê-Mirim estuary. We utilized a coupled wave-hydrodynamic model to predict the sediment transport and medium-term seabed evolution due to tidal flow, wave climatology, and river discharge. Model results are compared against the measured current in the upper estuary and sediment transport rate measured in the estuary's mouth.

\footnotetext{
${ }^{1}$ Department of Environmental Engineering, Federal University of Espírito Santo, Vitória, Espírito Santo, Brazil

${ }^{2}$ Department of Environmental Engineering, Federal University of Espírito Santo, Vitória, Espírito Santo, Brazil

${ }^{3}$ Department of Environmental Engineering, Federal University of Espírito Santo, Vitória, Espírito Santo, Brazil
} 
NUMERICAL MODEL

In this work, we set up the Delft3D numerical model using the coupled hydrodynamics and waves effects to compute the sediment transport and medium-term seabed evolution at the PiraquêAçú/Piraquê-Mirim estuary. The Delft3D is a finite difference model who solves the 3D or depthaveraged mass and momentum conservation equations in a staggered grid. This model includes the main hydrodynamic processes that modify the coastal morphology, such as tidal flow, wave-current interaction, wave induced currents, wind drag, density flow, etc.

\section{Model Physics}

The hydrodynamic model is given by the momentum (Eq. 1-2) and continuity (Eq. 3) equations for an incompressible fluid. In these equations, the Boussinesq and the long wave approximations are considered. These are the shallow water equations with hydrostatic pressure and may be solved in a rectilinear or curvilinear grid. The turbulence effects are computed employing the $\kappa-\varepsilon$ closure model. The horizontal background eddy viscosity and diffusivity are set to $1 \mathrm{~m}^{2} / \mathrm{s}$ (as in Brière et al., 2010).

$$
\begin{gathered}
\frac{\partial u}{\partial t}+u \frac{\partial u}{\partial x}+v \frac{\partial u}{\partial x}+g \frac{\partial \eta}{\partial x}-f v+\frac{g u U}{C^{2}(d+\eta)}-v_{W}\left(\frac{\partial^{2} u}{\partial x^{2}}+\frac{\partial^{2} u}{\partial y^{2}}\right)=0 \\
\frac{\partial v}{\partial t}+u \frac{\partial v}{\partial x}+v \frac{\partial v}{\partial y}+g \frac{\partial \eta}{\partial y}+f u+\frac{g v U}{C^{2}(d+\eta)}-v_{W}\left(\frac{\partial^{2} v}{\partial x^{2}}+\frac{\partial^{2} v}{\partial y^{2}}\right)=0 \\
\frac{\partial \eta}{\partial t}+\frac{\partial u h}{\partial x}+\frac{\partial v h}{\partial y}=0
\end{gathered}
$$

In which $C$ is the Chézy's friction coefficient $\left(\mathrm{m}^{1 / 2} / \mathrm{s}\right), d$ is the still water depth $(\mathrm{m}), \eta$ is the sea surface elevation $(\mathrm{m}), U$ is the velocity magnitude $(\mathrm{m} / \mathrm{s}), g$ is the acceleration due to the gravity $\left(\mathrm{m} / \mathrm{s}^{2}\right), v_{W}$ is the diffusion coefficient $\left(\mathrm{m}^{2} / \mathrm{s}\right), h$ is the total water depth $(\mathrm{m}), h=(d+\eta), u$ and $v$ are the depth-averaged velocity components in the $x$ and $y$ directions $(\mathrm{m} / \mathrm{s})$, respectively.

To account the effect of the wave on hydrodynamics and the hydrodynamics in the wave propagation we used the two-way online-coupled current-wave module. In this module, the hydrodynamic and wave are coupled in an user-defined time (couple time) in which updated water level, and velocities feed the wave module and the new wave radiation stresses resulting from the wave propagation are updated in the hydrodynamic module. The Delft3D-WAVE module is the third generation SWAN (Simulating Waves Nearshore) model (Holthuijsen et al., 1993).

The SWAN model computes the evolution of random, short-crested waves in coastal regions with deep, intermediate and shallow water and ambient currents utilizing the spectral action balance equation. The SWAN model accounts for refractive propagation due to current and depth and represents the processes of wave generation by wind, dissipation due to whitecapping, bottom friction and depth-induced wave breaking and non-linear wave-wave interactions (both quadruplets and triads) (more detail the reader can find in the Delft3D user manual - Deltares, 2014).

We calculated bathymetric changes using the Exner (1925) equation (Eq. 4). In each time step, bathymetry is updated and to extend the morphological time, we accelerated morphological changes using the morphological factor approach. It works multiplying the seabed sediment flux by a constant factor, thereby extending the morphological time step (more detail can be found in Lesser et al., 2004).

$$
(1-\varepsilon) \frac{\partial z_{b}}{\partial t}=f_{\text {morfac }}\left(D-E+\frac{\partial q_{b}}{\partial x}+\frac{\partial q_{b}}{\partial y}\right)
$$

In which $\varepsilon$ is the porosity, $z_{b}(\mathrm{~m})$ is the seabed height, $q_{b}$ is the seabed sediment transport rate $\left(\mathrm{m}^{3} / \mathrm{m} / \mathrm{s}\right)$ and $f_{\text {morfac }}$ the morphological acceleration factor.

To solve the bedload sediment transport we tested the formulations of Engelund \& Hansen (1967), van Rijn (1993), Soulsby \& van Rijn (Soulsby, 1997) and van Rijn (2007). Suspended sediment transport is solved using the advection-diffusion equation (Eq. 5): 


$$
\frac{\partial h c}{\partial t}+\frac{\partial u h c}{\partial x}+\frac{\partial v h c}{\partial y}-\frac{\partial}{\partial x}\left(h \varepsilon_{x} \frac{\partial c}{\partial x}\right)-\frac{\partial}{\partial y}\left(h \varepsilon_{y} \frac{\partial c}{\partial y}\right)=E-D
$$

Where $C$ is the suspended sediment concentration $\left(\mathrm{kg} / \mathrm{m}^{3}\right), \varepsilon_{X}$ and $\varepsilon_{y}$ are the sediment diffusion coefficients $\left(\mathrm{m}^{2} / \mathrm{s}\right), E$ and $D$ are the erosion and deposition fluxes $\left(\mathrm{kg} / \mathrm{m}^{2} / \mathrm{s}\right)$ calculated with the Araithurai-Partheniades equations (Partheniades, 1965; Ariathurai, 1974).

\section{Model Setup}

To simulate the hydrodynamics, wave induced currents, sediment transport and seabed evolution we set up the Delft3D model to the Piraquê-Açú/Piraquê-Mirim estuary. The model covers both Piraquê-Açú and Piraquê-Mirim rivers, extending to the depth of approximately $32 \mathrm{~m}$ seaward. We utilized an irregular curvilinear mesh with variable spacing, ranging from $15 \mathrm{~m}$ (in the estuary mouth) to $180 \mathrm{~m}$ and 18283 active points, as shown in the Fig. 1-a.

(a)

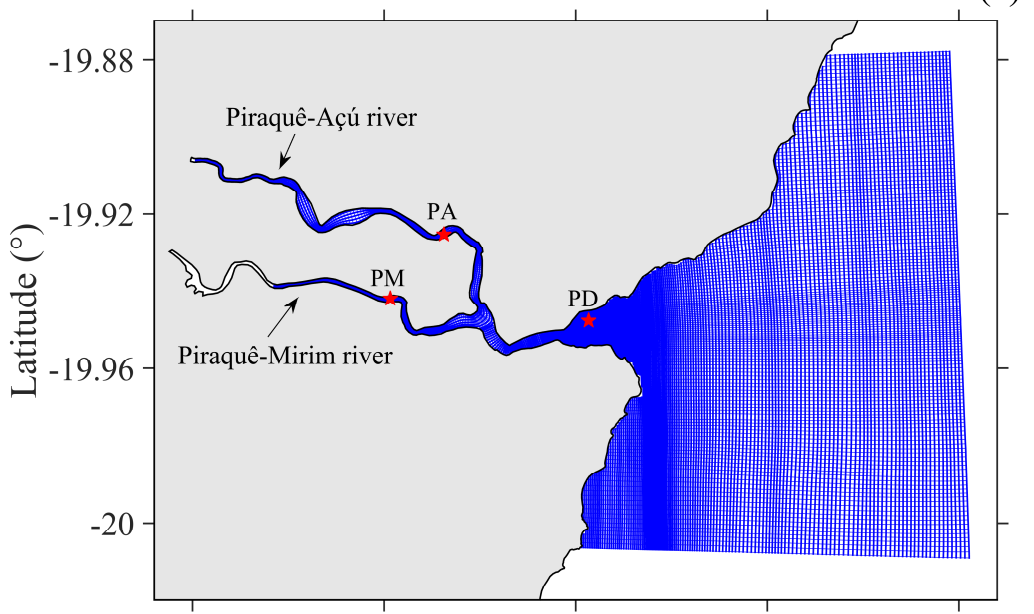

(b)
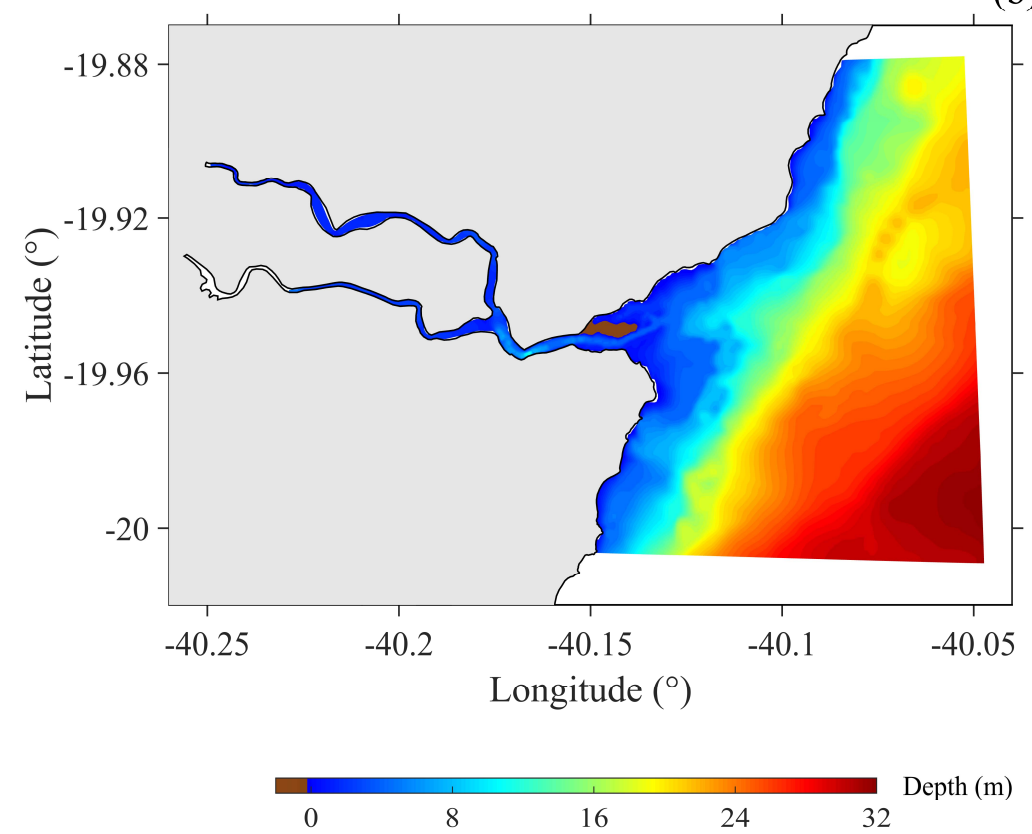

Figure 1. Numerical grid covering the Piraquê-Açú/Piraquê-Mirim estuary (a) and model bathymetry (b).

Bathymetry provided to the model (Fig. 1-b) is a blend of digitalized nautical charts (from Brazilian navy) and measured data from Silva et al. (2013). In the river boundaries, we imposed river flow measured in rainy period in both rivers. Along ocean boundaries, we set the Riemann boundary conditions (Verboom and Slob, 1984) using tidal elevations from the TPXO tidal inverse model 
considering 11 primary tidal harmonics. Since we interested in the effects of tidal flow and waves on sediment transport and morphological evolution, the wind and stratification are not considered.

The waves are propagated from the deep ocean to the coast using the Delft3D-WAVE module in a $100 \mathrm{~m}$ grid size regular mesh, where climatology from 40-years ECMWF reanalysis is set at the model boundary. In the coastal region, the results from the propagated wave climatology are set up in a mesh with a double grid size of that used for hydrodynamics simulations (Fig. 1-a). Table 1 shows wave climate set in the ocean grid and the coastal grid.

\begin{tabular}{|c|c|c|c|c|c|c|}
\hline \multirow[b]{2}{*}{ Season } & \multicolumn{3}{|c|}{ Ocean grid } & \multicolumn{3}{|c|}{ Coastal grid } \\
\hline & $H_{s}(\mathrm{~m})$ & $T_{p}(\mathrm{~s})$ & $\theta\left(^{\circ}\right)$ & $H_{S}(\mathrm{~m})$ & $T_{p}(\mathrm{~s})$ & $\theta\left(^{\circ}\right)$ \\
\hline Summer & 1.25 & 7.5 & 60 & 0.95 & 7.37 & 76 \\
\hline Autumn & 1.25 & 8.5 & 150 & 1.14 & 8.35 & 145 \\
\hline Spring & 1.75 & 8.5 & 120 & 1.63 & 7.35 & 120 \\
\hline Winter & 1.75 & 7.5 & 150 & 1.60 & 7.37 & 145 \\
\hline
\end{tabular}

The wave and the hydrodynamics models are coupled using the radiation stress gradient. Model coupling occurs at each 20 minutes' interval and the resulting hydrodynamics (currents and/or waves) feed the sediment transport model. In this module, we set variable seabed sediment grain size from Silva et al. (2003) and hypothetical $10 \mathrm{~m}$ of sediment layer thickness since we do not have stratigraphy data available. At river boundaries, we set zero suspended sediment flux and Neumann boundary conditions (zero gradient) in the ocean boundaries. Following Xie et al. (2013) we set the erosion $M=2.0 \times 10^{-5}\left(\mathrm{~kg} / \mathrm{m}^{2} / \mathrm{s}\right)$, critical hear stress equal to $0.2\left(\mathrm{~N} / \mathrm{m}^{2}\right)$ for erosion and $0.1\left(\mathrm{~N} / \mathrm{m}^{2}\right)$ for deposition and compared four sediment transport formulations: Engelund \& Hansen (1967), van Rijn (1993), Soulsby \& van Rijn (Soulsby, 1997) and van Rijn (2007).

The seabed sediment transport rate is the input of the morphological module, where the bathymetry is updated using the Exner (1925) equation. To compute the morphological changes, we simulated two months of hydrodynamics and extended the morphological changes to 5 years using a morphological acceleration factor equal to 28.51 .

To validate the model results we simulated hydrodynamics in spring and neap tide conditions and compared with measured data at the Piraquê-Açú river and in the Piraquê-Mirim river (PA and PM red stars in the Fig. 1-a) and modelled sediment transport rate is compared with measured transport in estuary mouth (PD red star in the Fig. 1-a).

\section{MODEL VALIDATION}

The comparison between modelled currents and measured data are shown in the Fig.2. We found a good agreement comparing the measured velocities and the model results in both rivers. The minimum and maximum velocities in the Piraquê-Mirim River in neap tide conditions are $0.1 \mathrm{~m} / \mathrm{s}$ and $0.16 \mathrm{~m} / \mathrm{s}$ (Fig. 2-a), respectively. The error in this case is around $0.05 \mathrm{~m} / \mathrm{s}$ comparing the predicted and measured velocities. At the Piraquê-Açú River (Fig. 2-a) the velocities reach magnitudes of $0.2 \mathrm{~m} / \mathrm{s}$, while minimum velocity is zero (model results), and the maximum error between model and measurements is equal to $0.1 \mathrm{~m} / \mathrm{s}$.

In spring tide conditions, we found the minimum and maximum velocities of $0.15 \mathrm{~m} / \mathrm{s}$ and $0.45 \mathrm{~m} / \mathrm{s}$, respectively in the Piraquê-Mirim River. The error between the measured and modelled results is equal $0.1 \mathrm{~m} / \mathrm{s}$ and we also found a good fit between modelled and measured data, as shown in the Fig. 2-c. At the Piraquê-Açú River, the results shown that the maximum and minimum velocities are similar to the Piraquê-Mirim River, as show in the Fig. 2-d, however the minimum velocities are equal to zero. Again, we found a good fit between modelled and measured curves (fig. 2-d).

The modelled sediment transport rates considering four sediment formulations and the measured data are shown in the Fig. 3. In this case, the formulation of Engelund and Hansen (1967) showed the best fit with measured data. However, the location of the measurements has no wave influence, and the hydrodynamics is driven only by river flow and tidal elevations. In this kind of environment, several authors pointed that the Engelund and Hansen (1967) formulation has the best performance, mainly in canalized tidal-river flow (Hibma et al., 2003; Hassanzadeh et al., 2011; Chen, 2014). 
(a)

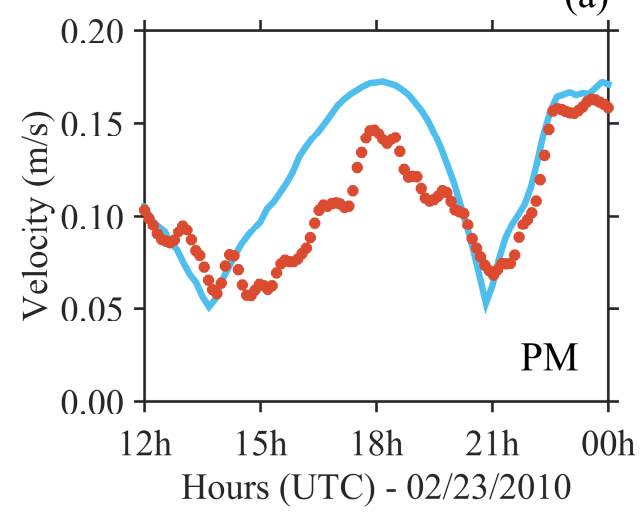

(b)

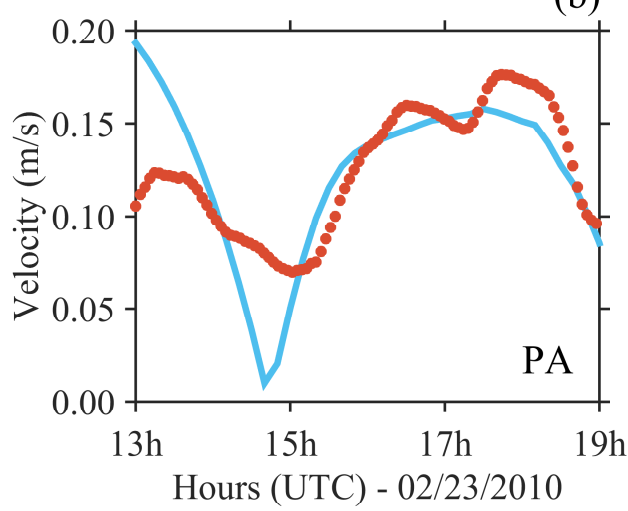

(c)

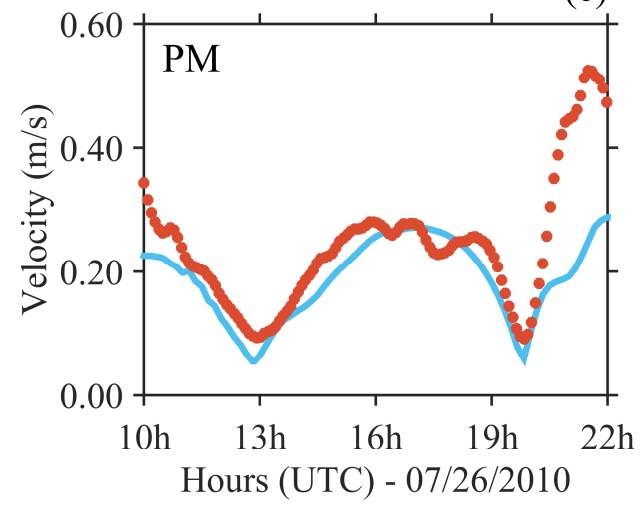

(d)

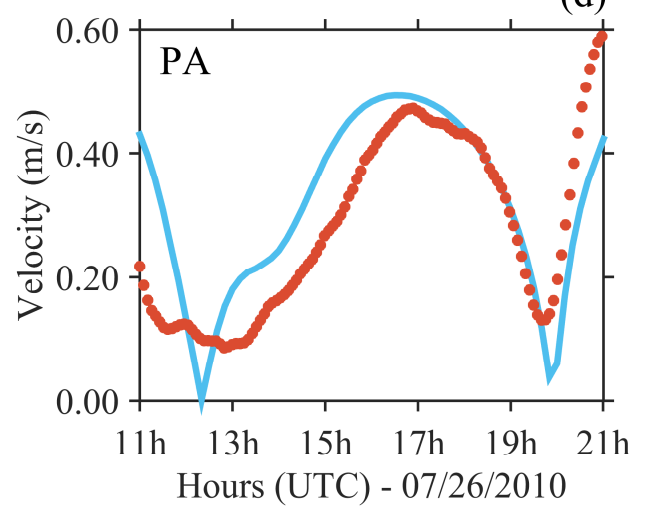

- Model results - Observed data

Figure 2. Modelled currents (blue line) and measured data (red dots) in the Piraquê-Mirim river (PM) and in the Piraquê-Açú river in neap and spring tide conditions. In (a) and (b) neap tide velocities and in (c) and (d) spring tide velocities.

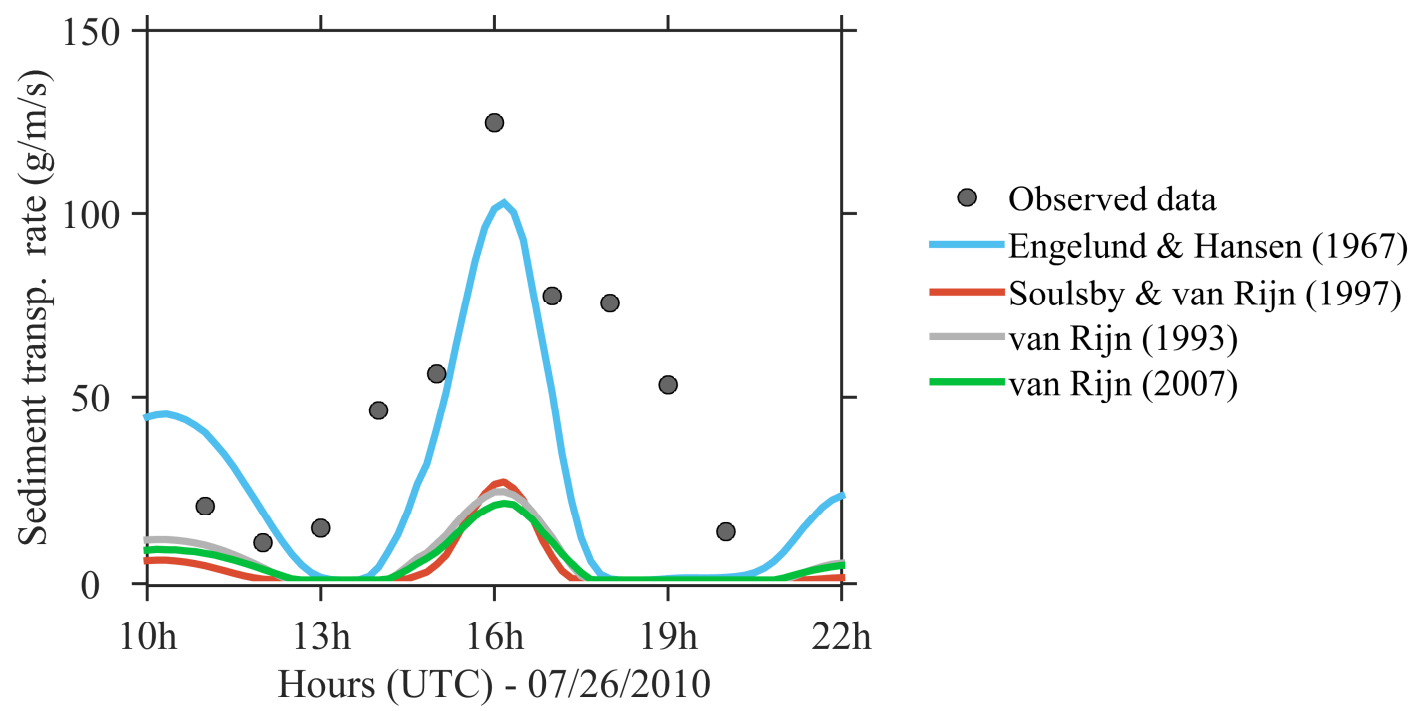

Figure 3. Modelled (lines) and measured (dots) sediment transport rate in the estuary mouth. 


\section{WAVE CLIMATE}

The wave climate (significant height and direction) modelled in the Piraquê-Açú/Piraquê-Mirim estuary for the four seasons are shown in the Fig. 4. The summer climatology is shown in the Fig. 4-a, in this period we observed the lower wave heights $(0.9 \mathrm{~m}$ in deep ocean) coming from the East toward the estuary mouth. In autumn, we observed the maximum significant height of $1.2 \mathrm{~m}$ coming from the Southeast quadrant. The winter (Fig. 4-c) and spring (Fig. 4-d) seasons have the higher wave heights in the study area (approximately $1.7 \mathrm{~m}$ in the offshore side of the domain in the depth of $30 \mathrm{~m}$ ) from the SE direction.

We observed a high wave refraction in waves coming from the southeast quadrant toward to the estuary mouth and the sandbank. The inlet shape and the sandbank has a significant role in dumping most of the wave energy in the estuary, as shown in the Fig. 4. Wave breaking occurs near to coastline and around the sandbank.
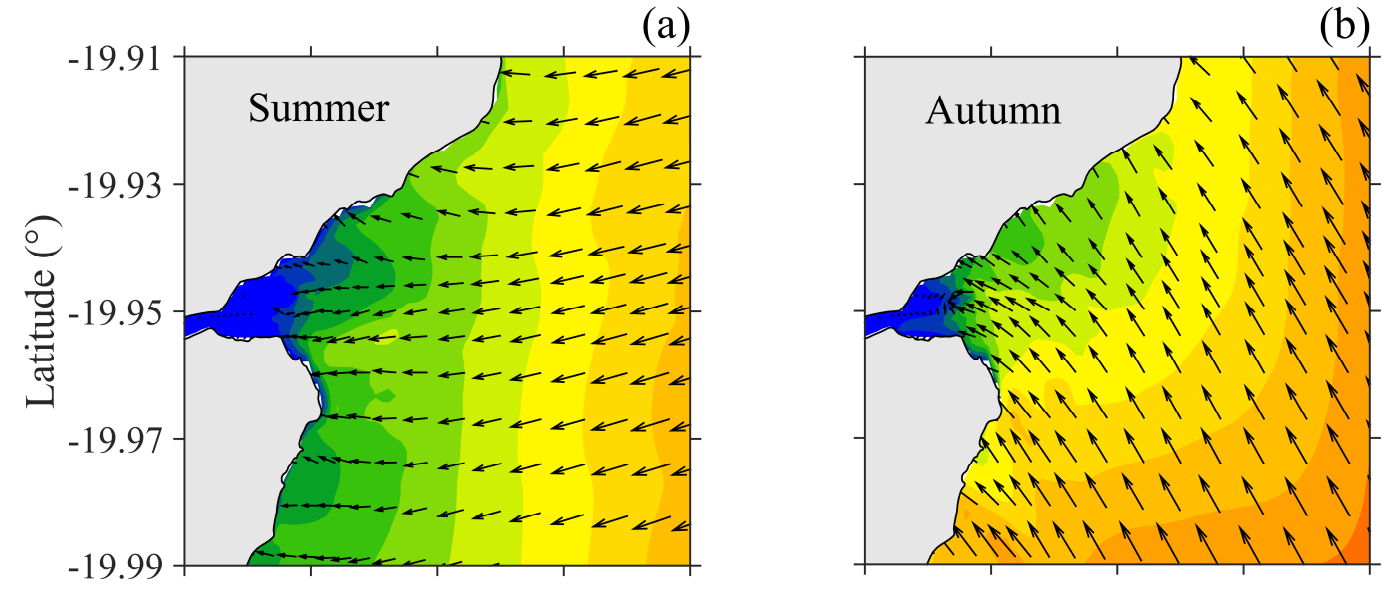

(c)

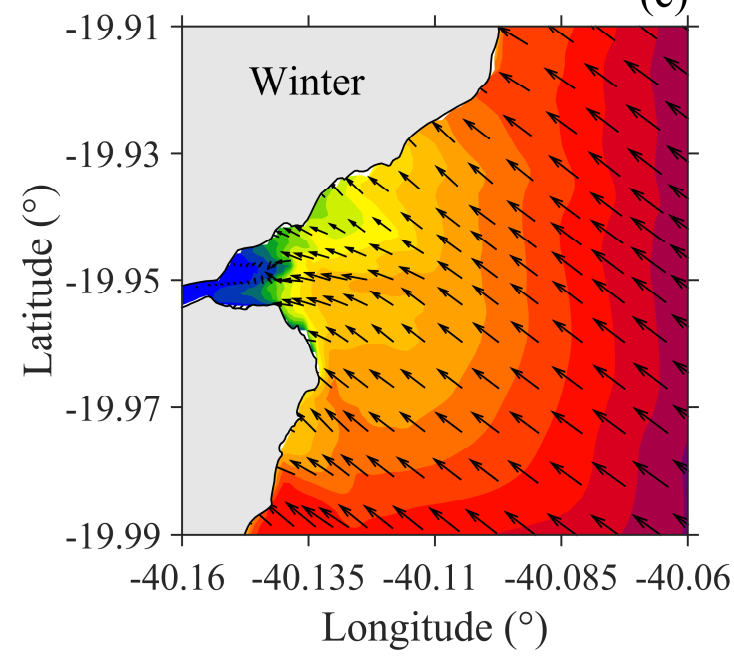

(d)
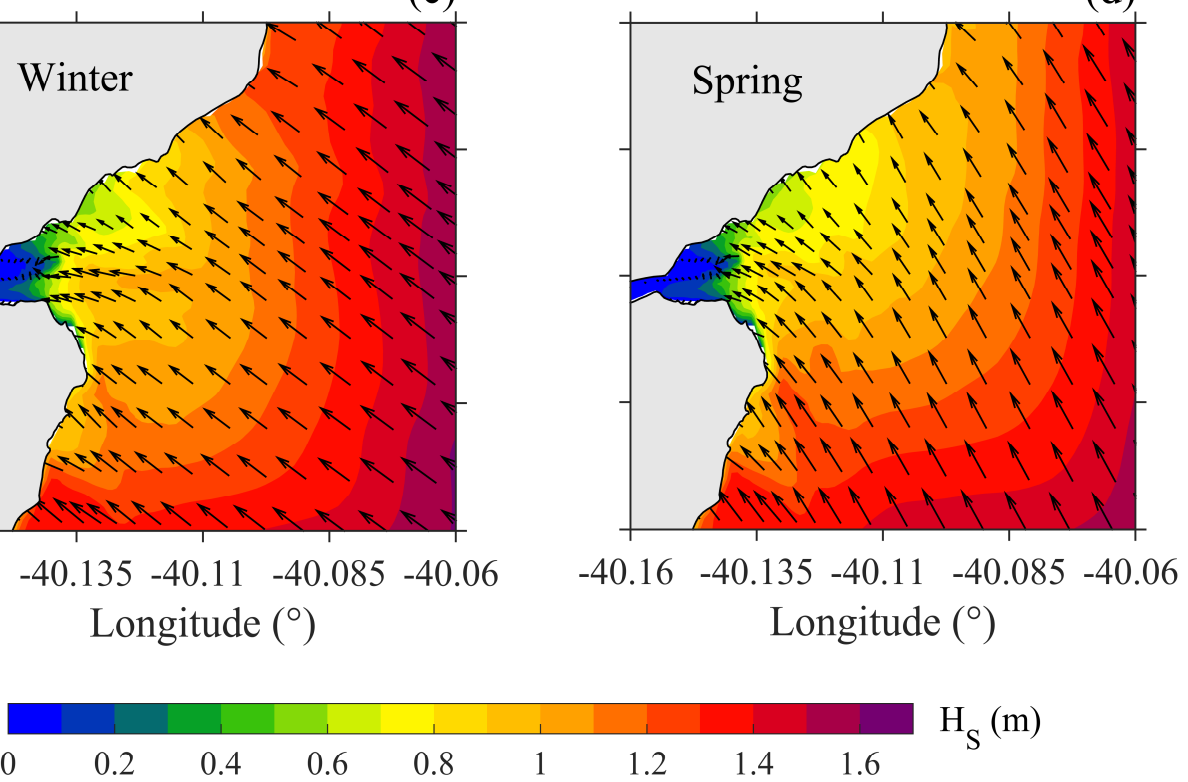

Figure 4. Modelled significant wave height $(m)$ and mean direction climatology in the Piraquê-Açú/PiraquêMirim estuary. In (a) Summer climatology, (b) Autumn climatology, (c) Winter climatology and (d) Spring climatology.

\section{HYDRODYNAMICS OF THE ESTUARY}

Fig. 5 shows the peak of ebb and flood tide velocities in spring tide conditions considering river and tidal forcing only (Fig. 5-a and Fig. 5-b) and with wave-induced currents (Fig. 5-c and Fig. 5-d). A snapshot of the depth-averaged currents during flood and ebb tide periods show the increasing of the 
velocities in the tidal channel next to the sandbank where the peak of velocities reaches magnitudes of $0.7 \mathrm{~m} / \mathrm{s}$ (Fig. 5-a and Fig. 5-b) due to mass conservation in the canalized flow of the river mouth.

We observe the effect of the wave in the generation of coastal currents (Fig. 5-c and Fig. 5-d). The $2 \mathrm{D}$ radiation stress modifies the pattern of the depth-averaged velocity especially near to the coast and the sandbank due to the strong wave stress and breaking in this region. The flow magnitude in the tidal channel slightly modifies since the sandbank dumps most of the wave energy. Coastal wave induced currents occur in most of the coastline and can be as strong as $0.6 \mathrm{~m} / \mathrm{s}$. These currents combined with tidal and river flow produces a jet that can reach the depth of $12 \mathrm{~m}$ in ebb tide conditions (Fig. 5-c).

Thus, model results suggest that tidal, and river flow dominate the tidal channel and the inner estuarine zone. Wave-induced circulations and alongshore currents prevail on the ebb tidal delta and in the nearshore region on both sides of the estuarine mouth. In the nearshore area away from the inlet, wave-induced circulation patterns often are driven by the interaction between waves and bathymetry similar to MacMahan et al. (2006) and Zhou et al. (2014).

\section{EBB}

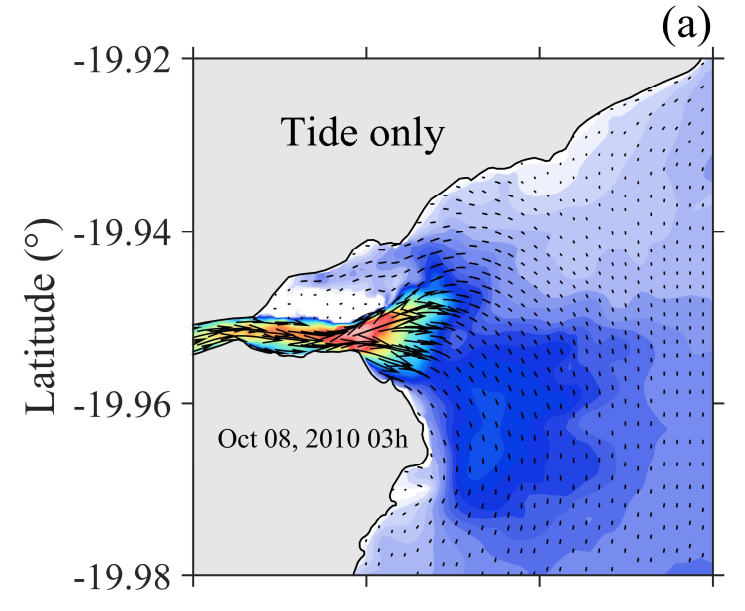

(c)

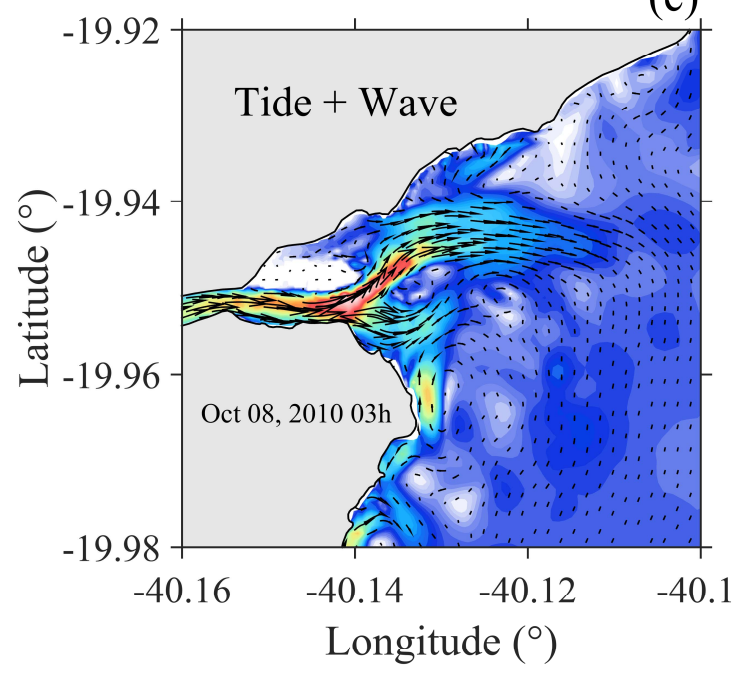

\section{FLOOD}

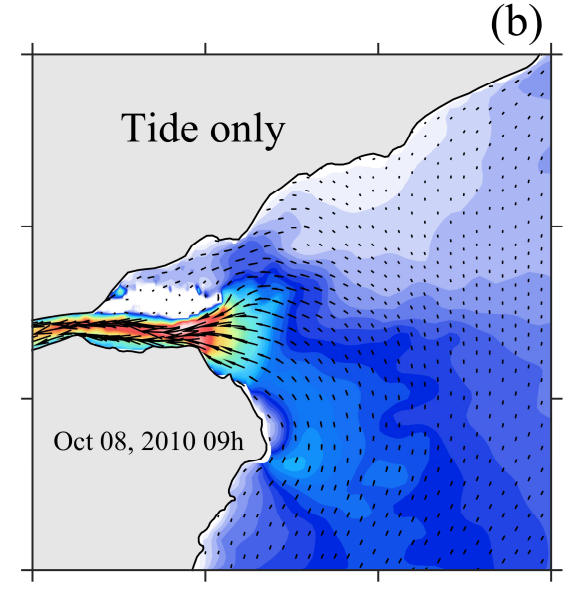

(d)

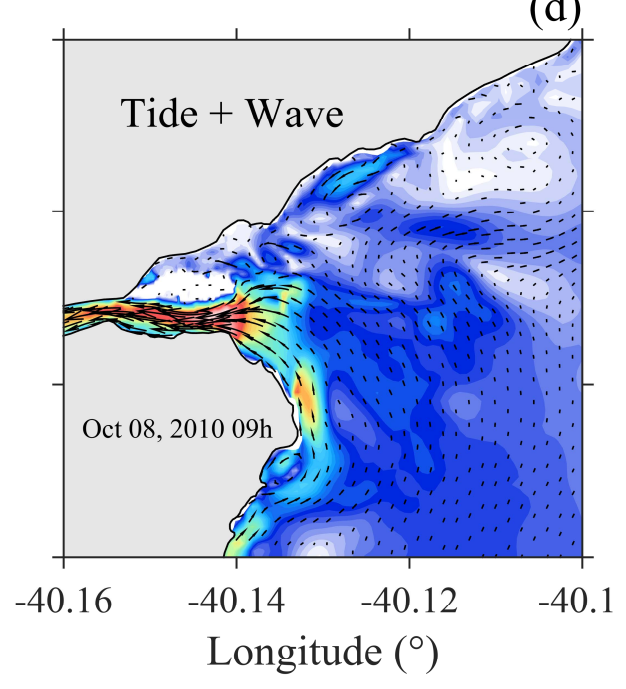

$(\mathrm{m} / \mathrm{s})$

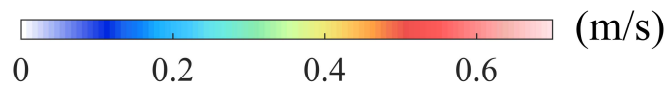

Figure 5. Peak of flood and ebb tide velocities. In (a) and (b) peak of ebb and flood tide velocities, respectively, considering tidal and river forcing only. In (c) and (d) peak of ebb and flood tide velocities, respectively, considering river flow, tide forcing and waves. 


\section{SEDIMENT TRANSPORT AND SEABED EVOLUTION}

Fig. 6 shows the tidally averaged/residual sediment transport rate in the Piraquê-Açú/PiraquêMirim estuary considering the tidal and wave effects since residual sediment transport driven by tidal flow is lower than $10 \mathrm{~g} / \mathrm{m} / \mathrm{s}$ (not shown). We evaluated the results from the van Rijn (2007) sediment transport formulation considering that formulation account the wave and current effects on sediment transport.

The residual sediment transport rate has a strong correlation with the currents induced by wave and tidal flow in ebb tide conditions (Fig. 5-c) probably due to the wave stirring (Kleinhans \& Grasmeijer, 2006), wave asymmetry, longitudinal currents (Cayocca, 2001) and the wave turbulence (Lesser et al., 2004). The direction of the sediment transport is toward to sandbank and, to the open sea (Fig. 6). In front of the sandbank, we found residual sediment transport rate in order of $50 \mathrm{~g} / \mathrm{m} / \mathrm{s}$ in the depth of $10 \mathrm{~m}$, while at the sandbank this transport is equal to approximately $25 \mathrm{~g} / \mathrm{m} / \mathrm{s}$. Model results suggest that the wave-induced and tidal currents drive the sediment toward to the river mouth, especially in the main channel. The model simulations also indicate that tide appears to be ebbdominant and the sediments are exported seaward in the tidal cycle.

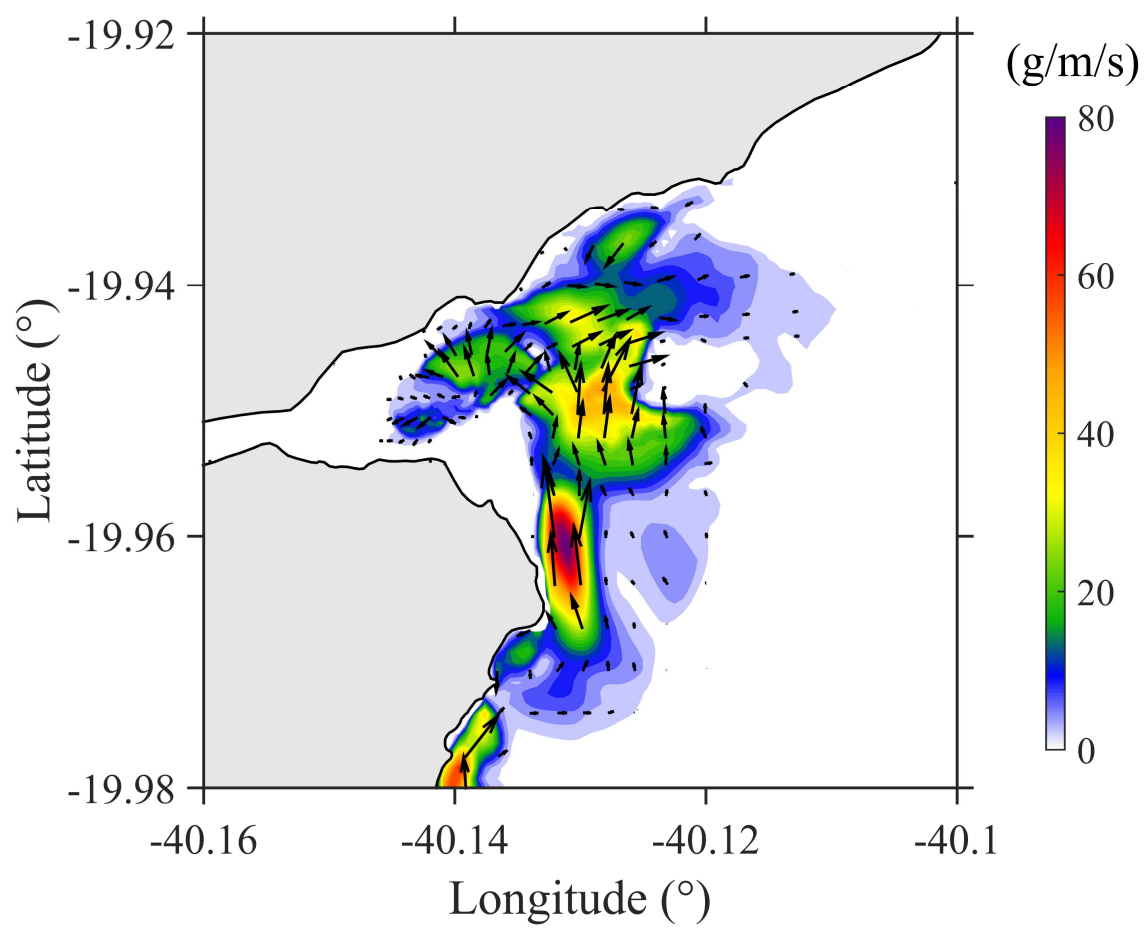

Figure 6. Tidally averaged sediment transport rate in the Piraquê-Açú/Piraquê-Mirim Estuary.'

The resulting morphological response is a pattern of deposition and erosion in the estuary mouth similar to the sediment transport field. Fig. 7 shows the pattern of accretion and erosion in the PiraquêAçú/Piraquê-Mirim estuary during one year (Fig. 7-a), two years (Fig. 7-b), four years (Fig. 7-c) and five years (Fig. 7-d). Fig. 8 shows the bathymetric profiles measured in the estuary mouth.

We observed a strong erosion in sandbank near to the main tidal channel; this is probably in function of the wave breaking and current transport in this region. Model results suggest that in the sandbank an erosion of $3 \mathrm{~m}$ in five years (Fig. 7-d). All area seems to experience erosion trends, mostly in the margins of the estuary.

We used the seabed sediment mass conservation equation to calculate the seabed changes, since this equation assumes that the seabed has a wave-like movement, the eroded material is deposited near to erosion sites (as shown in the Fig. 7). The accretion of material is in order of $3 \mathrm{~m}$ with seaward movement, mainly in front of the sandbank. The results also suggest that the sandbank is migrating to the north; in this case, eroded material trend to deposit between the sandbank and the coastline where the velocities are too weak to transport the sediment. This can be seen comparing the evolution of the bathymetric profiles in the river mouth (Fig. 8), where we can notice that the bathymetric lines are moving toward to the "B" location (Fig. 8), the north coastline. In the other side, we found a strong erosion of the sandbank slope probably due to wave breaking. 
(a)

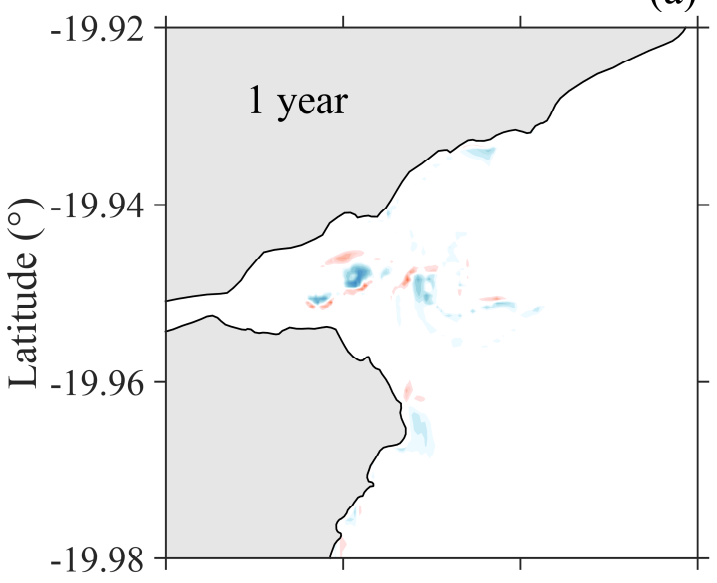

(c)

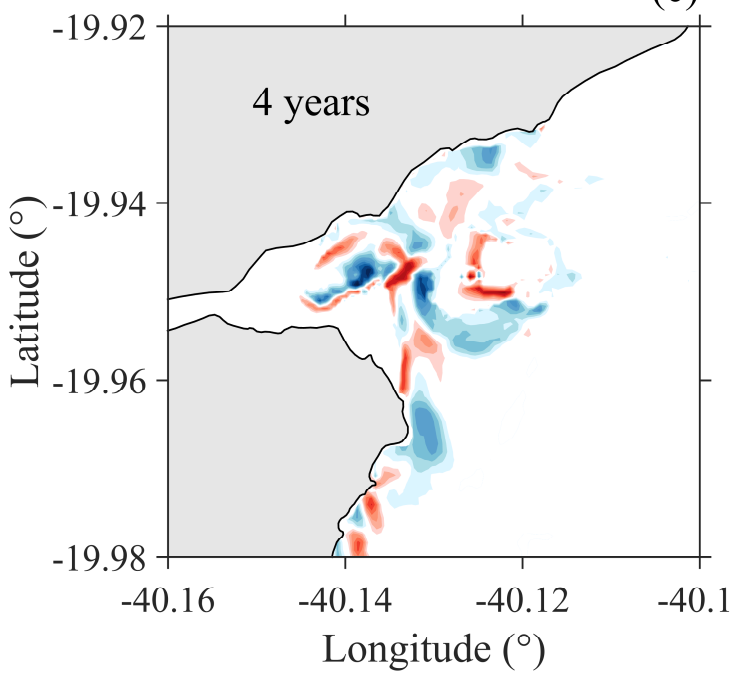

(b)

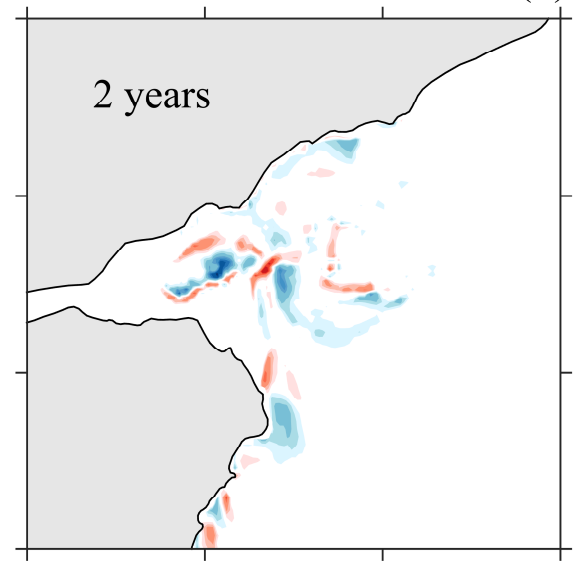

(d)

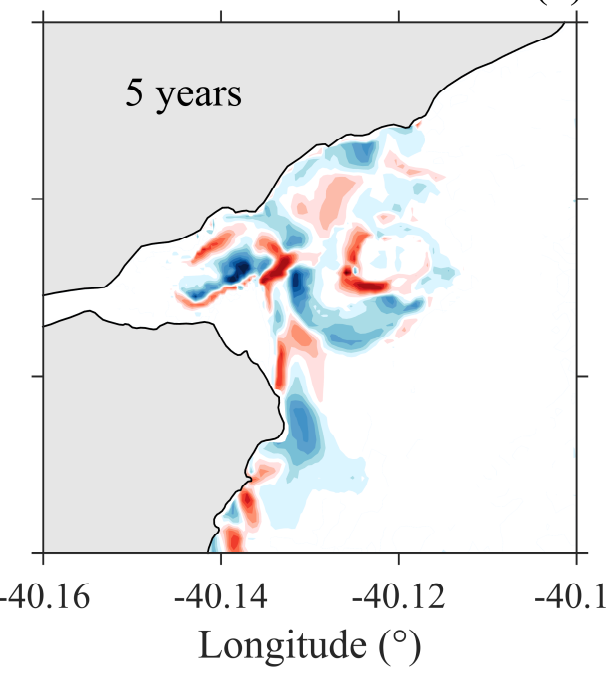

Erosion (m)

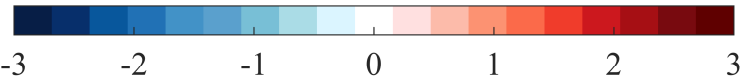

Deposition (m)

Figure 7. Cumulative sediment erosion and deposition for one year (a), two years (b), four years (c) and five years (d).
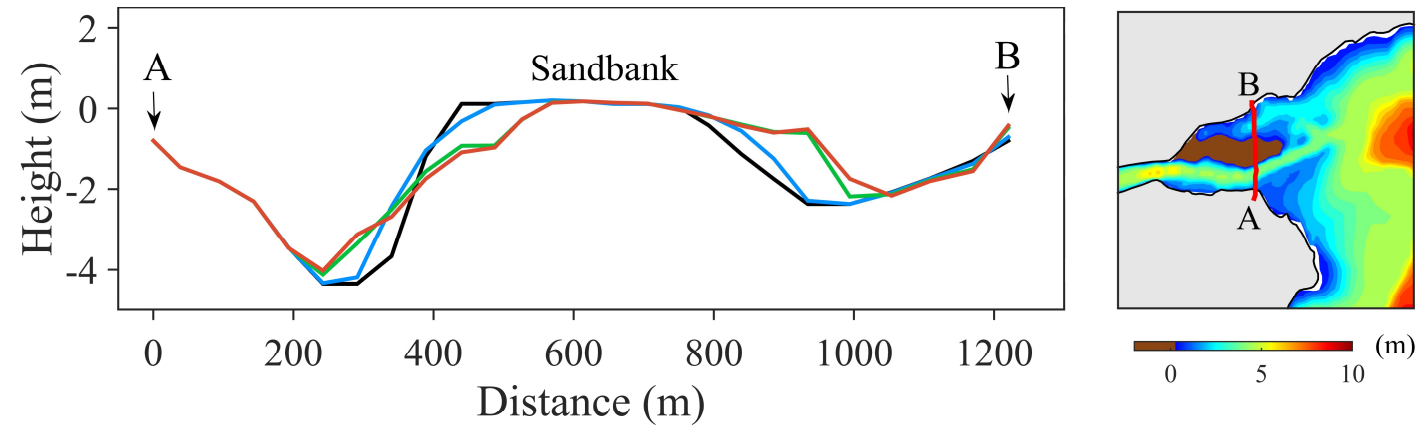

- Initial profile - 1 year - 3 years -5 years

Figure 8. Modelled bathymetric profiles at the estuary mouth (line A-B). Initial profile is the black line, 1-year profile is the blue line, 3-years profile is the green line and the red line represents the 5-years bathymetric profile. 


\section{CONCLUSION}

In this work, we computed the tidal and river flow hydrodynamics, wave climatology, wave induced currents, sediment transport a medium-term seabed evolution using the Delft3D models. We found an excellent agreement with measured currents and sediment transport in the estuary. River and tidal flow control the hydrodynamics of estuary, due to sandbank wave dumping effect. Waves play an important role in sediment transport, mostly in the region around the sandbank and in the coastline.

Model results suggest that coastal sediment transport is driven mainly by tidal-wave currents. Waves drive overall seabed changes in the PiraquêAçú/Piraquê-Mirim estuary. Consequently, the major seabed changes were observed around the sandbank, who seems to be migrating to the north.

The morphodynamics of the Piraquê-Açú/Piraquê-Mirim estuary is very complex, and we utilized some simplifications in the numerical model. Although the results were validated, they require more research on additional factors that may contribute to the sediment transport and seabed evolution.

\section{ACKNOWLEDGMENTS}

We would like to thank Professor Gilberto Barroso from the Department of Oceanography of the Federal University of Espírito Santo to make river flow data available. Leonardo Carvalho de Jesus and Thaís Nunes Coutinho are graduate students funded by CAPES (Coordenação de Aperfeiçoamento de Pessoal de Nível Superior).

\section{REFERENCES}

Ariathurai, C. R. 1974. A finite element model for sediment transport in estuaries. Ph.D Thesis, University of California, Davis.

Bertin, X., A. Oliveira, and A.B. Fortunato. 2009. Simulating morphodynamics with unstructured grids: description and validation of a modeling system for coastal applications, Ocean Modelling, 28 (1-3), 75-87.

Brière, C., P.C. Roos, E. Garel and S.J.M.H. Hulscher. 2010. Modelling the morphodynamics of the Kwinte Bank, subject to sand extraction. Journal of Coastal Research, 51, 117-126.

Cayocca, F. 2001. Long-term morphological modeling of a tidal inlet: the Arcachon Basin, France, Coastal Engineering, 42 (2), 115-142.

Chen, F. 2014. Analysis of the effects of process variations on delta morphology and stratigraphy in Delft3D computational models. Thesis of master degree. Faculty of Civil Engineering and Geosciences. Delft University of Tecnology. Delft.

da Silva, A., V. da Silva Quaresma, and A. Bastos. 2013. Sedimentological Sectorization of an Estuarine System In A Regressive Coast, Southeast Brazil. Journal of Sedimentary Research, 83(11), 994-1003.

Ding, Y. and S.S.Y Wang. 2006. Development and validation of a quasi-three-dimensional coastal area morphological model, Journal of waterway, port, coastal, and ocean engineering, 132, 462-476.

Dissanayake, D., A. Wurpts, M. Miani, H. Knaack, H. Niemeyer, and J. Roelvink. 2012. Modelling morphodynamic response of a tidal basin to an anthropogenic effect: Ley Bay, East Frisian Wadden Sea - applying tidal forcing only and different sediment fractions, Coastal Engineering, 67, 14-28.

Dissanayake, D., J. Roelvink, and M. van der Wegen. 2009. Modelled channel patterns in a schematized tidal inlet, Coastal Engineering, 56, 1069-1083.

Engelund, F. and F. Hansen. 1967. A Monograph of Sediment Transport in Alluvial Channels. Teknisk Forlag, Copenhagen.

Exner, F. M. 1925. Über die Wechselwirkung zwischen Wasser und Geschiebe in Flüssen (On the interaction between water and sediment in streams), Sitzungsber. Akad. Wiss. Wien Math. Naturwiss., Abt. 2A, 134, 165-205.

Fortunato, A., A. Nahon, G. Dodet, A. Rita Pires, M. Conceição Freitas, N. Bruneau, A. Azevedo, X. Bertin, P. Benevides, C. Andrade, and Oliveira. 2014. Morphological evolution of an ephemeral tidal inlet from opening to closure: The Albufeira inlet, Portugal, Continental Shelf Research, 73, 49-63.

Hassanzadeh, H., S. Faiznia, M.S. Bajestan, and A. Motamed. 2011. Estimate of sediment transport rate at Karkheh River in Iran using selected transport formulas. World Applied Sciences Journal, 13 (2), 376-384.

Hibma, A., H.J. de Vriend, and M.J.F. Stive. 2003. Numerical modelling of shoal pattern formation in well-mixed elongated estuaries. Estuarine coastal and shelf science, 57, 981-991. 
Holthuijsen, L.H., N. Booij and R.C. Ris. 1993. A spectral wave model for the coastal zone, 2nd International Symposium on Ocean Wave Measurement and Analysis, New York, 630-641.

Kleinhans, M. G., and B.T. Grasmeijer. 2006. Bed load transport on the shoreface by currents and waves. Coastal Engineering, 53, 983-996.

Kuang, C., X. Liu, J. Gu, Y. Guo, S. Huang, S. Liu, W. Yu, J. Huang, and B. Sun. 2013. Numerical prediction of medium-term tidal flat evolution in the Yangtze Estuary: Impacts of the Three Gorges project, Continental Shelf Research, 52, 12-26.

Lesser, G. R., J.A Roelvink, J.A.T.M. Kester, and G.S. Stelling. 2004. Development and validation of a three-dimensional morphological model, Coastal Engineering, 51, 883-915.

Longuet-Higgins M.S. and Stwart R. W. (1960) Changes in the form of short gravity waves on long waves and tidal currents, Jounal of Fluid Mechanics, 8, 565-583.

MacMahan, J., E. Thornton, A. Reniers, T. Stanton, and G. Symonds. 2008. Low-Energy Rip Currents Associated With Small Bathymetric Variations. Marine Geology, 255(3-4), 156-164.

Olabarrieta, M., W.R. Geyer, and N. Kumar 2014. The role of morphology and wave-current interaction at tidal inlets: An idealized modeling analysis. Journal of Geophysical Research, Oceans, 119(12), 8818-8837.

Partheniades, E. 1965. Erosion and deposition of cohesive soils. Journal of the Hydraulics Division Proceedings of the ASCE, 9, 105-139.

Soulsby, R., 1997. Dynamics of marine sands. Thomas Telford, UK, 249p.

Van Der Vegt, M., H.M. Schuttelaars, H.E. De Swart. 2006. Modelling the equilibrium of tidedominated ebb-tidal deltas. Journal of Geophysical Research, 111, F02013.

Van Rijn V. 1993. Principles of sediment transport in rivers, estuaries and coastal seas. Aqua Publicantions, Amsterdam, 700p.

van Rijn, L.C. 2007. Unified view of sediment transport by currents and waves. I: initiation of motion, bed roughness, and bed-load transport, Journal of Hydraulic Engineering, 133, 649-667.

Verboom, G. K., and A. Slob. 1984. Weakly-reflective boundary conditions for two-dimensional shallow water flow problems. Advance Water Resources, 7, 1693-1708.

Wang, Z., T. Louters, and H. de Vriend. 1995. Morphodynamic modelling for a tidal inlet in the Wadden Sea, Marine Geology, 126(1-4), 289-300.

Xie, D., S. Gao, Z. Wang, and C. Pan. 2013. Numerical modeling of tidal currents, sediment transport and morphological evolution in Hangzhou Bay, China. International Journal of Sediment Research, 28, 316-328.

Zhou, Z., G. Coco, M. Jiménez, M. Olabarrieta, M. van der Wegen, and I. Townend. 2014. Morphodynamics of river-influenced back-barrier tidal basins: The role of landscape and hydrodynamic settings. Water Resources Research, 50(12), 9514-9535. 